Chapter 3

\title{
Monitoring of Water Leakages from Pipes through Geophysical Imaging Methods
}

\author{
Meropi Manataki, Nikos Papadopoulos, \\ Apostolos Sarris, Athos Agapiou, \\ Kyriacos Themistocleous and \\ Diofantos G. Hadjimitsis
}

Additional information is available at the end of the chapter

http://dx.doi.org/10.5772/59532

\section{Introduction}

Electrical Resistance Tomography (ERT) and Ground Penetrating Radar (GPR) are among the near-surface geophysical methods that are suitable for mapping the subsurface. As with all the geophysical methods, the ability of ERT and GPR methods to provide images of buried structures relies on the contrast of soil properties. The former provides images of the subsurface by measuring the electrical resistivity, while the latter records the time arrivals of electromagnetic pulses that are affected mostly by the differences of soil electrical properties. Since water leaks cause changes in soil electrical properties, it is feasible for water leakages to be detected without the need or soil drilling.

In this chapter, the results of controlled experiments for monitoring leakages from water pipes are presented. ERT and GPR were both applied in a test field site at Lakatameia Municipality to monitor the change of subsurface physical properties due the infiltration of water within the soil matrix. Time-lapse mode for both techniques was used to monitor the flow progress of the water within the ground surface due to the controlled leakage from a water pipe. These geophysical techniques were chosen as the most appropriate for meeting the needs of the research, the geomorphological characteristics of the site and the expected subsurface archaeological targets with regards to the detection and mapping of the targets. 


\section{Electrical Resistivity Surveying principles}

Resistivity surveying ${ }^{1}$ is one of the most commonly applied technique of geophysical survey in the Mediterranean due to its suitability in detecting walls, cavities, layers and other localized structures of differing electrical, permittivity and electrochemical properties (Mares, 1984). The electrical resistivity method has been applied with great success in solving hydrogeological (Dahlin and Owen, 1998), geological (Atzemoglou et al., 2003), engineering (Dahlin et al., 1994), mineral (Legault et al., 2008), environmental (Ramirez et al., 1996), archaeological survey problems (Papadopoulos et al., 2006) and detecting leaks from buried pipes (Jordana et al., 2001).

From the methodological point of view, in geoelectric surveys, a direct current or an alternating current of low frequency $(<100 \mathrm{~Hz})$ is fed into the ground by two metallic current electrodes with low stake resistance. This causes a potential field, which is influenced by the distribution of the specific resistivities in the earth. Measurements of differences of the potential field are carried out between two well-grounded, non-polarizable potential electrodes configuration. By applying special evaluation software, information about the distribution of resistivities and the geological structures can be derived. The term "apparent resistivity" is frequently used in the interpretation of resistivity data in order to overcome difficulties arising from inhomogeneous ground.

Electrode array or configuration refers to the specific way that the four electrodes are placed on or inside the ground in order to complete a specific resistivity measurement. Linear arrays, where the electrodes are placed along a line, are the most common due to the relative simplicity of the measured signals. The selection of the appropriate array for a given survey depends on diverse factors like the size of the survey, the nature and depth of the targets, the properties of the subsoil, the type of equipment, the depth of investigation and the array's behaviour characteristics (Weymouth and Huggins, 1985).

The method is normally employed in mapping mode employing a fixed electrode configuration moving along multiple parallel profiles forming a grid giving the horizontal distribution of subsurface resistance in a constant depth. This technique is very common in the exploration of archaeological sites mapping cultural and architectural buried relics (Aspinall and Lynam, 1970). Multi-probe, wheeled and tractor-based systems have also been able to speed up resistivity surveying and cover extensive areas mainly in smooth and conductive soils (Panissod et al., 1998).

The fixed electrode separation imposes specific limits for the maximum investigation depth that are closely related to the distance between the electrodes. The current flows along arcshaped paths that connect the two electrodes and, by increasing the electrode spacing, more of the injected current will flow to greater depths. Thus, when depth information is needed, the vertical electrical sounding can measure the vertical distribution of the resistance (i.e. the

1 Vertical Resistivity Soundings (VES), Resistivity Profiles (LP) and Electrical Resistivity Tomography (ERT) 
depth of a feature) by increasing the electrode separation and at the same time keeping the center of the configuration stable.

By combining along a line multiple profiles, with increasing electrode distances or alternatively multiple soundings with different centers, it is possible to record the vertical and horizontal distributions of resistivity along transects producing a two-dimensional (2-D) vertical resistivity section of the subsurface. In the cases of complex geology, artefacts may be generated in the two dimensional sections due to the three-dimensional (3-D) nature of the underground structures. This problem can only be resolved with the collection of full 3-D measurements where a finite number of electrodes are placed on the nodes of a rectangular grid and the potentials caused by a single current injection are measured at the remaining electrodes in all the different directions.

However, due to the logistics, full 3-D surveys cannot be applied on a routine basis. Therefore, even today the most common practice for recording the 3-D subsurface resistivity variation is to gather dense, parallel 2-D lines with the inter-line spacing equal to the basic inter-electrode spacing along a single or orthogonal directions (Papadopoulos et al., 2007). In the past 25 years, the development of the technology related to multiplexed electrode arrangements, automatic measuring systems and processing algorithms have resulted in the evolvement of Electrical Resistivity Tomography (ERT) technique (Loke et al., 2013).

The arrival of fast and powerful computers, in combination to the non-linear and ill-condition nature of the resistivity problem, has generated the necessity of developing automated modeling and inversion algorithms to process and interpret the resistivity data. These algorithms involve the reconstruction of the subsurface resistivity distribution which is consistent with the experimental data through an iterative optimization procedure that imposes smoothness or blocky constraints in order to stabilize the inversion procedure and produce a reliable resistivity model (Loke and Barker, 1996, Loke et al., 2003, Papadopoulos et al., 2011).

ERT can also be used to monitor dynamic processes that evolve in the ground by installing permanent electrodes in fixed positions. In such cases, time lapse resistivity surveys or 4-D imaging techniques (Karaoulis et al., 2011; Kim et al., 2009) approach the spatial changes of the subsurface resistivity distribution over time. In general these resistivity changes can only be mapped and monitored only if substantial spatial-temporal changes of the measured apparent resistivity exist. Typical examples of such approaches are the flow of water through the vadose zone, the flow of chemical pollutants, the vertical variations of the water table, etc. A number of different approaches have been proposed for the efficient processing and interpretation of 4-D imaging ERT data (e.g. independent inversions, ratio of inverted data from initial and later data sets, difference inversions, and least-squares regularization).

\section{Ground Penetrating Radar (GPR) principles}

Ground Penetrating Radar (GPR) is a non-destructive electromagnetic (EM) geophysical technique that uses radio waves, in the frequency range of $10 \mathrm{MHz}$ to $2 \mathrm{GHz}$, to map the 
subsurface. The first reported attempt of using radio wave signals to measure subsurface features was by El-Said, (1956) who tried to image the depth of a water table. The development of the method accelerated considerably after 1970 as a result of the tremendous progress that took place in electronics and computer technology (Annan, 2002).

GPR can be used in a series of applications like the mapping of the bedrock depth (Davis and Annan, 1989), the determination of the stratum thickness and the aquifer depth (Doolittle et al., 2006), the location of physical and artificial cavities in the subsurface (Benson, 1995) and fracture zones (Grasmueck, 1996; Theune et al., 2006). Recently the method is also used in archaeological prospection for the detection of buried antiquities (Papadopoulos et al., 2009; Spanoudakis et al., 2011; Vaughan, 1986). Additionally, GPR has been used for locating both buried pipes and water leakages providing promising results (Bimpas et al., 2010; Hunaidi et al., 1999; Powers and Olhoeft, 1996; Stampolidis et al., 2003).

The operation principle of GPR lies on the interaction between the EM energy and the matter, and has specific similarities with the seismic reflection method. High frequency pulses of short duration are injected into the ground by a transmitter antenna. Those pulses or signals are "traveling" into the subsurface until they hit a boundary of a different material. Part of the energy is reflected back to the surface and recorded by the receiver antenna, while the remaining energy is diffused at deeper levels. This boundary or reflector is defined by the contrast on the electrical properties of the subsoil's materials, the conductivity and permittivity, which affect the wave's propagation. The receiver records the amplitude of the reflected signal with respect to the travel time, i.e. the time that the signal needed to reach the receiver from the transmitter. Basically the method depends on the record of the waves reflected on surfaces that divide regions with different electrical properties.

The time between the transmitting and the receiving pulse depends on the velocity along the trace the pulse followed. The paths that an emitted signal can follow in the case of two layers with different electrical properties are illustrated in Figure 1. Since the time is measured, if the electromagnetic wave propagation velocity is known, then the depth of the reflector can be determined. In most geological materials, the conductivity and the dielectric constant (relative permittivity) are the main parameters that affect the pulse. Conductivity affects the energy absorption, thus the signal penetration and the depth of the investigation, while permittivity affects the velocity of the signal. In general, GPR is most useful in low-electrical-loss materials (i.e. very low conductivity values). Clay-rich environments or areas of saline water will affect negatively the method's efficiency (Cassidy, 2009a).

Besides the electrical properties of subsoil's materials, the penetration depth of GPR depends also from the central frequency of the emitted pulses. The absorption increases with frequency and thus a smaller frequency is used for detecting the deeper targets. However, the resolution of the method is decreased as the frequency is increased. For instance, a GPR system working at the range of $25-50 \mathrm{MHz}$ can investigate depths over 50 meters in soils with low conductivity (smaller than $1 \mathrm{~ns} / \mathrm{m}$ ) like sand and gravels.

The data are collected by moving the configuration of transmitter and receiver (common offset) along a profile on the surface. The recordings produce a 2D image of the subsurface (Distance 


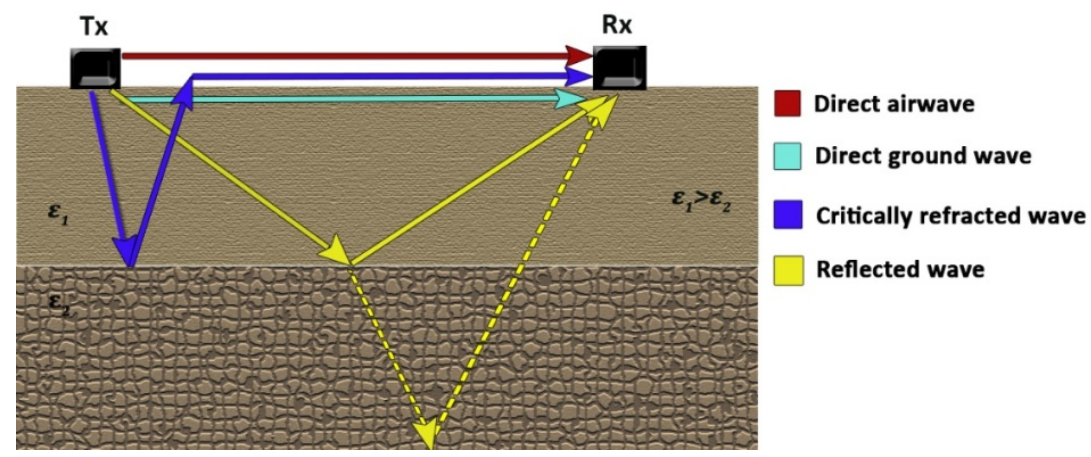

Figure 1. Signal paths between the transmitter (Tx) and the receiver (Rx) for two layers with different electrical properties. The dashed yellow line indicates that part of the signal's energy was refracted and then reflected (Annan, 2009).

(m)-Time (ns) or Depth (m)) that is called radargram or section (Fig. 2a). When working in grids of constant line spacing, 3D images of the subsurface are obtained out of which depth slices can be are extracted (Fig. 2b). Depth slices are also 2D images that provide the horizontal information of the subsoil with increasing depths.

Data processing of GPR data can be divided into two major stages: (1) the processing of the radargrams where signal processing techniques are used and slices are extracted and (2) the processing of slices where image processing corrections are applied. More emphasis is given to the first stage that aims to filter the noise from the data and enhance the reflections of the raw data. Some standard processes that are usually applied regardless the field of application, are (Cassidy, 2009b):

Traces reposition that corrects the position of GPR traces included in a survey line. This correction is useful to eliminate systematically offsets in survey lines' starting and ending positions that is usually occurred in rough terrains.

Timezero correction which allows to estimate the correct vertical position of the first pulse that left the antenna and entered the subsurface (Tzanis, 2006).

Dewow filter which removes low frequency noise derived by low frequency energy near transmitter and is associated with electrostatic and inductive fields.

SEC (Spreading \& Exponential Compensation) gain that enhance signals located at greater depths and have much smaller amplitude compared with that of the shallower signals.

Background subtraction filter: that reduces random noise from the data and also removes the direct waves and ringing noise.

Hilbert Transform in order to calculate the instantaneous amplitude (Spanoudakis and Vafidis, 2010). 


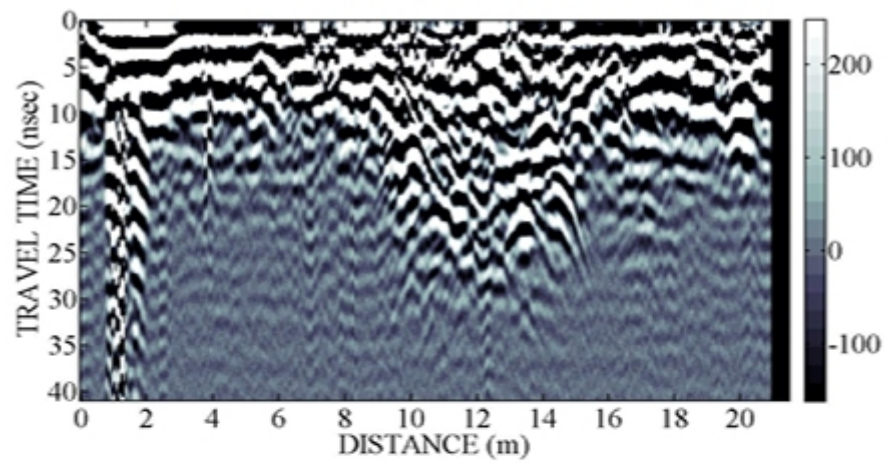

(a)

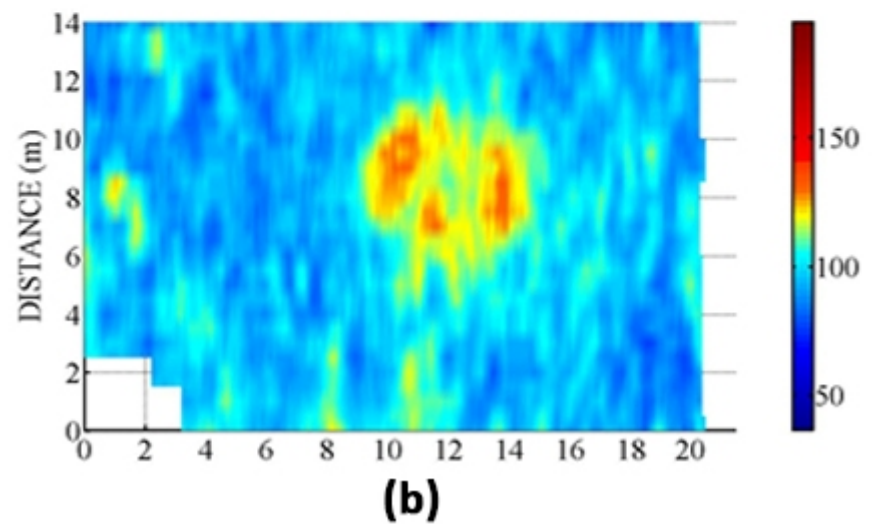

Figure 2. Images of buried roman cistern located at Aptera archaeological site where (a) is a GPR section while (b) is a GPR slice revealing the shape of the cistern at the depth of 1,0 m. PulseEKKO 1000 with a 400MHz was employed with $0.5 \mathrm{~m}$ spacing between the transects (Spanoudakis et al., 2011)

\section{Case study: Lakatameia Municipality}

The test site is located at Lakatameia Municipality of Cyprus (Fig. 3a). An area of 420 square meters $(15 \times 28 \mathrm{~m})$ within the green dashed polygon (Fig. $3 \mathrm{~b})$ was surveyed and monitored with both ERT and GPR. Water was injected to the ground through pipe 1 (Fig. $3 \mathrm{~b}$ ) to create a controlled water leakage located approximately at $2-3 \mathrm{~m}$ depth. Time lapse mode was used for both methods. The geophysical monitoring mapping survey of the site was conducted for a period of two days in the beginning of summer of 2013. 

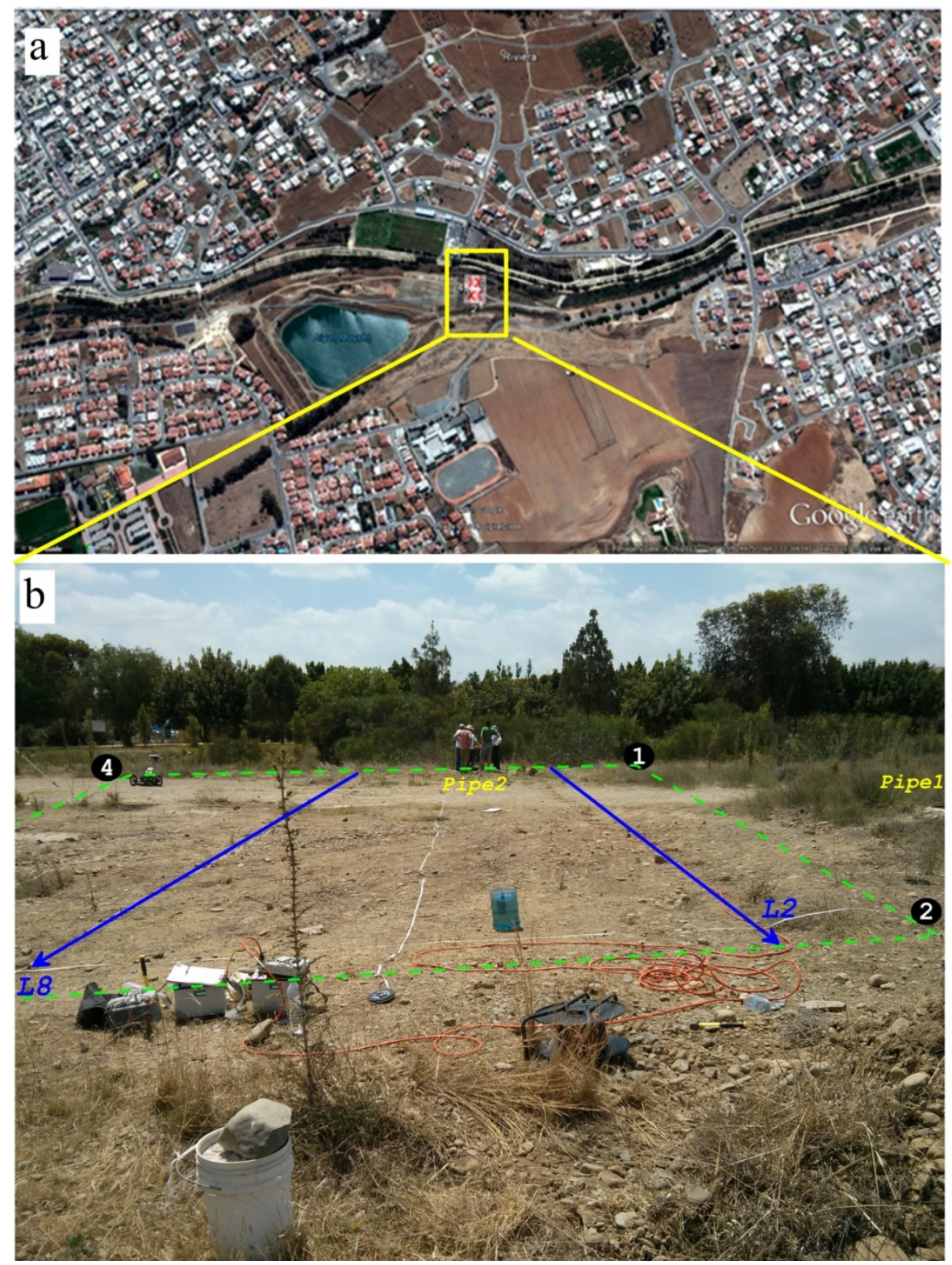

Figure 3. Google Earth satellite image of Lakatameia Municipality (Cyprus) showing the area where the monitoring experiment was conducted. b) The dashed polygon outline the geophysical survey area. The blue arrows indicate the direction of the surface ERT lines that were used to monitor the water leakage that was initiated from Pipe 1. 


\subsection{Instrumentation and Data acquisition}

A specific map coordinate system was chosen for the geophysical grid, which was registered to the appropriate geodetic system of coordinates (local coordinate system), based on the Total Station mapping data. Thus, after the rectification of the satellite image, the geophysical maps can be overlaid at their corresponding location.

For ERT, the Iris Syscal Pro and Switch Pro 96s was used (Fig. 4a) while for the GPR, the Noggin Plus Smart Cart was employed, equipped with a $250 \mathrm{MHz}$ antenna (Fig. 4b). The expecting investigation depth is 5.0-6.0m for ERT while 2.0-3.0m for GPR. The geophysical survey parameters for both methods are summarized in Table 1 , while the data acquisition is described in the following paragraphs.
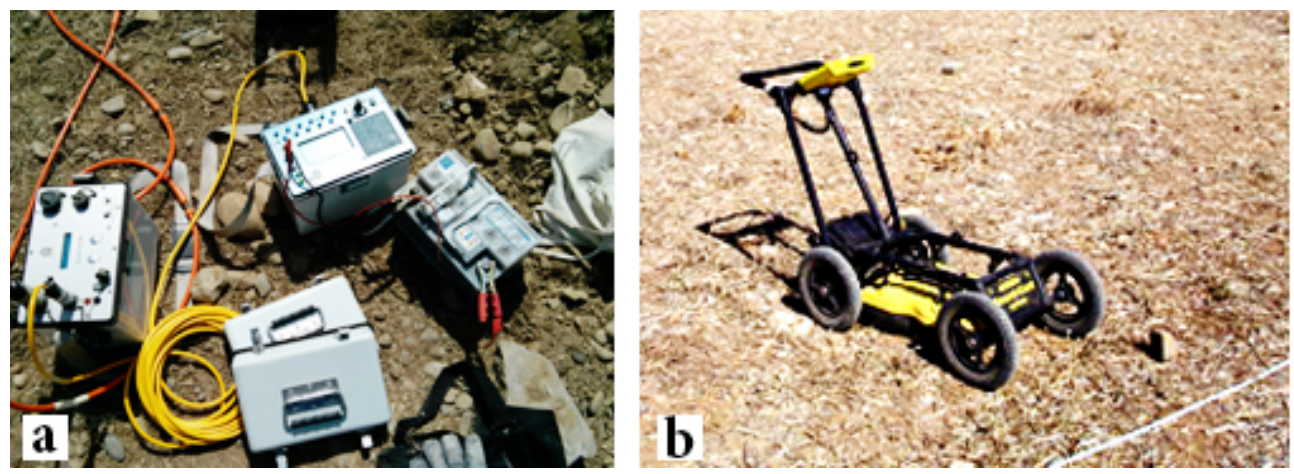

Figure 4. Details of the geophysical instrumentation that was used in the prospection at Lakatamia Municipality where a) ERT instrumentation and (b) GPR system equipped with $250 \mathrm{MHZ}$ antenna.

\begin{tabular}{cccc}
\hline Method & $\Delta \mathbf{x}(\mathbf{m})$ & $\Delta \mathbf{y}(\mathbf{m})$ & Area Coverage \\
\hline $\begin{array}{c}\text { GPR } \\
\text { Monitoring survey, 13 phases }\end{array}$ & $0.5,1.0$ & 0.025 & $420 \mathrm{~m}^{2}$ \\
\hline $\begin{array}{c}\text { ERT } \\
\text { static survey, }\end{array}$ & 1.0 & 2 & $392 \mathrm{~m}^{2}$ \\
8 parallel ERT lines, Dipole-Dipole array \\
29 electrodes in each line, Length of lines; 28m
\end{tabular}

\section{ERT}

monitoring survey,

2 lines (L2 \& L8), Dipole-Dipole array

29 electrodes in each line, Length of lines; $28 \mathrm{~m}$

9 Monitoring phases

Table 1. Technical details of the geophysical survey parameters. 


\subsection{ERT geophysical survey}

The first day was devoted to completing a static 3-D ERT survey by collecting 9 parallel ERT lines (L1 to L9). Each line was 28 meters long and 29 electrodes were placed along each transect in equally spaced intervals $(\mathrm{a}=1 \mathrm{~m})$. The inter-line separation was 2 meters covering in this way the whole area of interest. The Dipole-Dipole electrode array was chosen to capture the apparent resistivity measurements using the same configuration protocol for all the individual lines $(a=1 m, 1 a$ : Nsep=1a-8a, 2a: Nsep=1/2a-15/2a \& 1a-8a, 3a: Nsep=8/3a-16/3a). The goal of this survey was to map the stratigraphy and compile a model of the site regarding the main lithological layers up to the depth of about 5-6 meters below the ground surface.

The monitoring survey took place during the second day. The controlled water leakage from the pipe 1 (Fig. 3b) was initiated at 10:10 am and terminated four and a half hours later at 14:40 hours (Table 2). The reference ERT measurements for Lines L2 and L8 (Fig. 3b) were acquired at 10:11am and 10:44am respectively. The protocol which was used for the static ERT survey was also implemented for both lines and all the time phases. Thus the actual time for the data acquisition along each line was the same for all the snapshots that were taken (7-8 minutes).

\begin{tabular}{|c|c|c|c|c|c|c|}
\hline & \multicolumn{4}{|c|}{ L2 } & \multicolumn{3}{c|}{ L8 } \\
\hline & \multicolumn{5}{|c|}{ Leakage Initiation: 10:10 (Jne13th, 2013) } \\
\hline Phase & start & end & duration & start & end & duration \\
\hline T1 & $10: 11$ & $10: 19$ & $00: 08$ & $10: 44$ & $10: 51$ & $00: 07$ \\
\hline T2 & $10: 56$ & $11: 04$ & $00: 08$ & $11: 12$ & $11: 19$ & $00: 07$ \\
\hline T3 & $11: 24$ & $11: 31$ & $00: 07$ & $11: 41$ & $11: 48$ & $00: 07$ \\
\hline T4 & $11: 56$ & $12: 03$ & $00: 07$ & $12: 12$ & $12: 20$ & $00: 08$ \\
\hline T5 & $12: 24$ & $12: 31$ & $00: 07$ & $12: 36$ & $12: 43$ & $00: 07$ \\
\hline T6 & $12: 50$ & $12: 57$ & $00: 07$ & $13: 03$ & $13: 11$ & $00: 08$ \\
\hline T7 & $13: 19$ & $13: 27$ & $00: 08$ & $13: 43$ & $13: 50$ & $00: 07$ \\
\hline T8 & $14: 08$ & $14: 15$ & $00: 07$ & $14: 21$ & $14: 28$ & $00: 07$ \\
\hline T9 & $14: 33$ & $14: 40$ & $00: 07$ & $14: 44$ & $14: 52$ & $00: 08$ \\
\hline & \multicolumn{6}{|c|}{ End of 由T Monitoring: 14:52 (June13th, 2013) } \\
\hline
\end{tabular}

Table 2. Details regarding the initiation/termination time of the water leakage initiated the starting/ending point for 9 different time phases that were used to monitor the leakage.

\subsection{GPR geophysical survey}

GPR was employed on the second day, simultaneously with ERT. The first grid (GRID0) was measured before the beginning of the water leakage. Parallel lines were used with $0.5 \mathrm{~m}$ spacing, starting from point 1 while the orientation was the same with ERT lines (Fig. 5). The 
rest of the grids (12 in total) were collected in different times after the initiation of the leakage. The line spacing for the monitoring grids is $1.0 \mathrm{~m}$ and the starting / ending point was at $4.0 \mathrm{~m}$ and $12.0 \mathrm{~m}$ respectively. The challenge with GPR is to test whether it is capable of providing information about the water leakage without including the pipe and check its effectiveness to monitor water leakages directly from the subsoil.

\section{X (m)}



Figure 5. Area coverage of the GPR-ERT monitoring. 


\section{Data processing}

A specific workflow was used to process the ERT and GPR geophysical data. The raw geophysical data were entered in a portable PC right after fieldwork. ERT data processing is divided into two phases, the static survey and monitoring survey. GPR filters and corrections were initially applied on each section in order to improve the signal to noise ratio and enhance the reflections. Following, the differences between the first (dry soil) and the second phase (start of the water leakage) were calculated to examine the changes in the subsoil due to the water flow.

\subsection{ERT data processing}

The static resistivity data were processed with a 3-D resistivity inversion algorithm (Papadopoulos, et al., 2011) that converged to a final resistivity model after 5 iterations and RMS $=3.8 \%$. A generalized and systematic way was used to process the time lapse ERT data that collected along the lines L2 and L8. The extreme noisy apparent resistivity measurements were removed through specific despiking filters. The time-lapse data were subjected to diverse processing methodologies in order to determine the most appropriate one. Within the time-lapse inversion procedure the following constraints were tested:

No constraints: The data for the time-lapse survey were processed independently. Then the changes of the subsurface resistivity values are determined by comparing the model resistivity values obtained from the inversions of an initial data and the later time data sets.

A damped least-squares constraint to minimize the differences in the model resistivity values between the initial model and the time-lapse model.

A Least-squares smoothness constraint to ensure that the differences in the model resistivity values vary in a smooth manner.

Robust constraints to minimize the absolute changes in the model resistivity values.

The tests with the various inversion techniques using different constraints showed comparative results resulting in smooth subsurface monitoring images. Robust constraints showed relatively sharper inversion models. After the completion of the time-lapse inversions, the percentage change in the model resistivity obtained from the inversion of a later time data set compared to a reference model was plotted for all the different time snapshots. For direct comparison of the relative resistivity change during the time phases, a common range was used for all the plots.

\subsection{GPR data processing}

The sections that derived from Sensors \& Software Noggin Plus Smart Cart with $250 \mathrm{MHz}$ antennas were processed using MATLAB and the packages GPR-Pro (Spanoudakis and Vafidis, 2010) and MAT-GPR (Tzanis, 2006). For each section, the following corrections were applied in order to enhance the signal: 
Time zero correction in order to define the initial useful signal from each line. This determination was based on the intensity percentage of the first reflected wave (5-30\%).

Dewow filter to remove low frequency noise derived from the antenna.

SEC gain to enhance reflections located in greater depths.

Background noise removal filter to remove ringing and random noise that gain function highlighted.

The processed sections for each grid were placed appropriately in a three dimensional array $X(m), Y(m), Z(n s)$ according to the chosen local reference system that was used for the site, resulting in 13 volumes that represent the subsoil of the monitoring site for the different time lapses. Then the instantaneous envelope was estimated via Hilbert Transform and an average filter was applied for smoothing the results. The slices for GRID0 were extracted assuming a velocity for the electromagnetic waves equal to $0.1 \mathrm{~m} / \mathrm{nsec}$, while for the rest of the grids the velocity was estimated from the existing hyperbolas because the presence of water changes the electromagnetic waves velocity.

Next, the following procedures took place in order to emphasize the water flow:

Procedure 1: Percentage differences using GRID0 as a reference.

Procedure 2: Percentage differences using GRID1 as a reference.

At the resulting volumes, slices were extracted with a step of $0.25 \mathrm{~m}$ and colour maps were also applied.

\section{Results}

The 2-D resistivity section obtained from the static resistivity data (Fig. 6a) and extracted from the 3-D model shows generally a stratified earth with local superficial inhomogeneity. The range of the resistivity values between 50-300 Ohm-m signify a gravel/sandy layer from the surface up to the depth of $3 \mathrm{~m}$. The underlying horizon that exhibits lower resistivity signature (10-50 Ohm-m) is attributed to a silt and clay layer with sand. The low resistivity region along the section $(X=7-12 \mathrm{~m} / \mathrm{Z}=0-1 \mathrm{~m})$ is related to a modern ditch that has been excavated during the installation of Pipe 2 in the area and it appears in all the parallel lines (Fig. 6b). The general geologic setting that was extracted from the 3-D ERT survey regarding the uppermost gravel/ sandy layer is in quite agreement with in situ observation of the sediments from a natural subsurface cross-section observed at the edge of site (Fig. 6c).

The reference ERT measurements for Line 2 began at 10:11am. Approximately one hour (11:04am - end of Phase T2) after the controlled leakage began, the subsurface resistivity properties started to exhibit fluctuations of approximately 6-7\% decrease of resistivity. This decrease was registered along the horizontal distance $X=4-8$ meters and at a depth of more than 1.2 meters. As the monitoring of site continues, the resistivity decrease was more pronounced within the same region during the later phases. By the end of the experiment at 

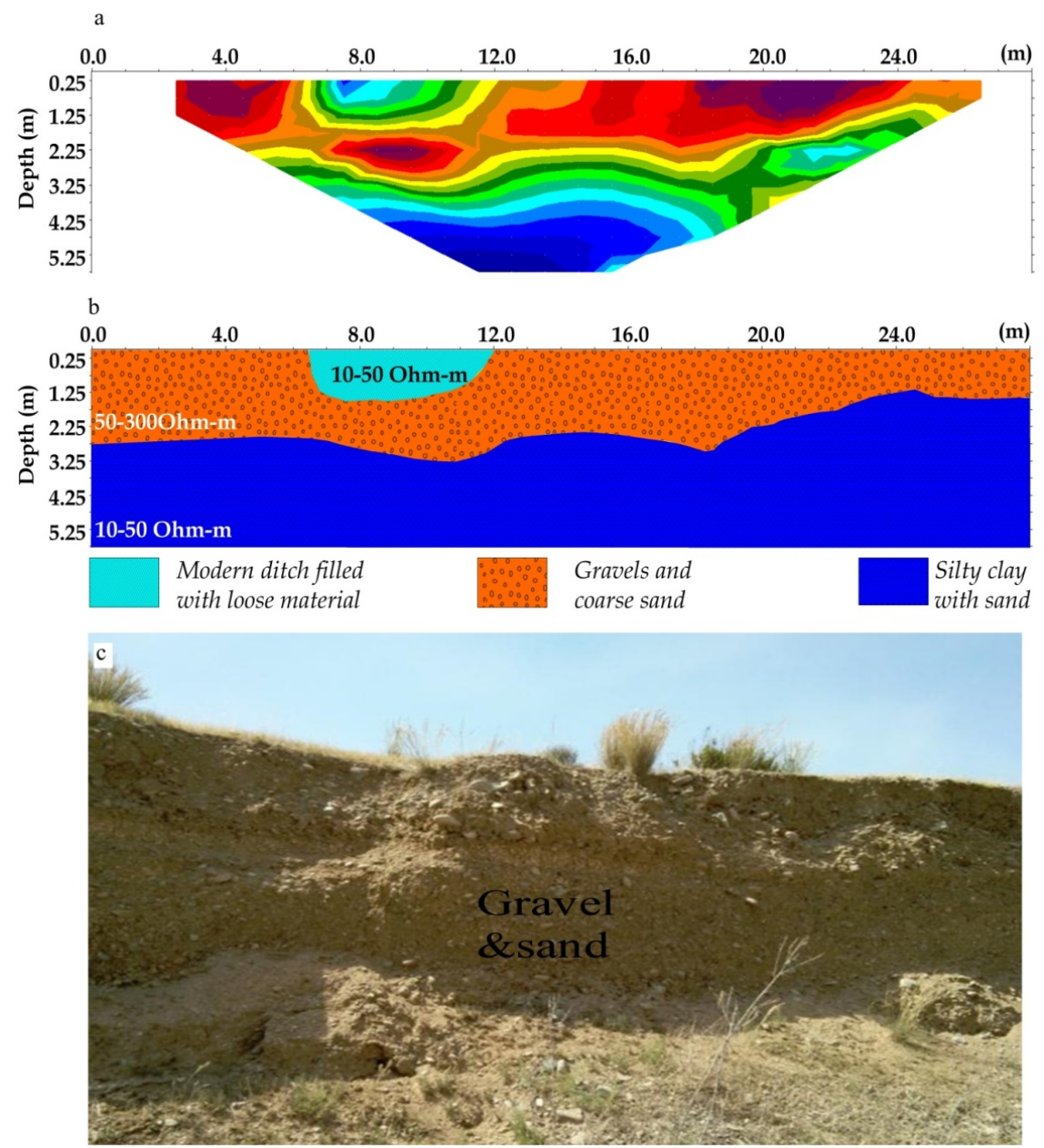

Figure 6. a) 2D resistivity section that was extracted from the 3-D inversion model. b) Geologic interpretation of the different geoelectrical units. c) In situ stratigraphic layers showing the gravel and sand layer.

14:40, the resistivity signature decreased to more than $20 \%$. Concurrently, after the 4 th time phase, the ERT measurements also show a resistivity decrease that was formulated within a circular region at the middle of the section $(X=13-15 \mathrm{~m}, \mathrm{Z}>2.5 \mathrm{~m})$. The resistivity decrease initiates from a value of about $6 \%$ at 12:03 hours by the end of Phase T4 and reaches almost $16-18 \%$ at the end of the experiment. A similar signature was registered along the profile L8, where within four hours of monitoring $(10: 44 \mathrm{pm}-14: 52)$ the resistivity was decreased more than $20 \%$ (Fig. 7). The area that is occupied by the drop of resistivity lies within the horizontal distance $X=8-11 \mathrm{~m}$ and depth more than one meter. A similar signature also appears at the beginning of the Line $8(X=4-6.5 \mathrm{~m})$ (Fig. 7$)$. 

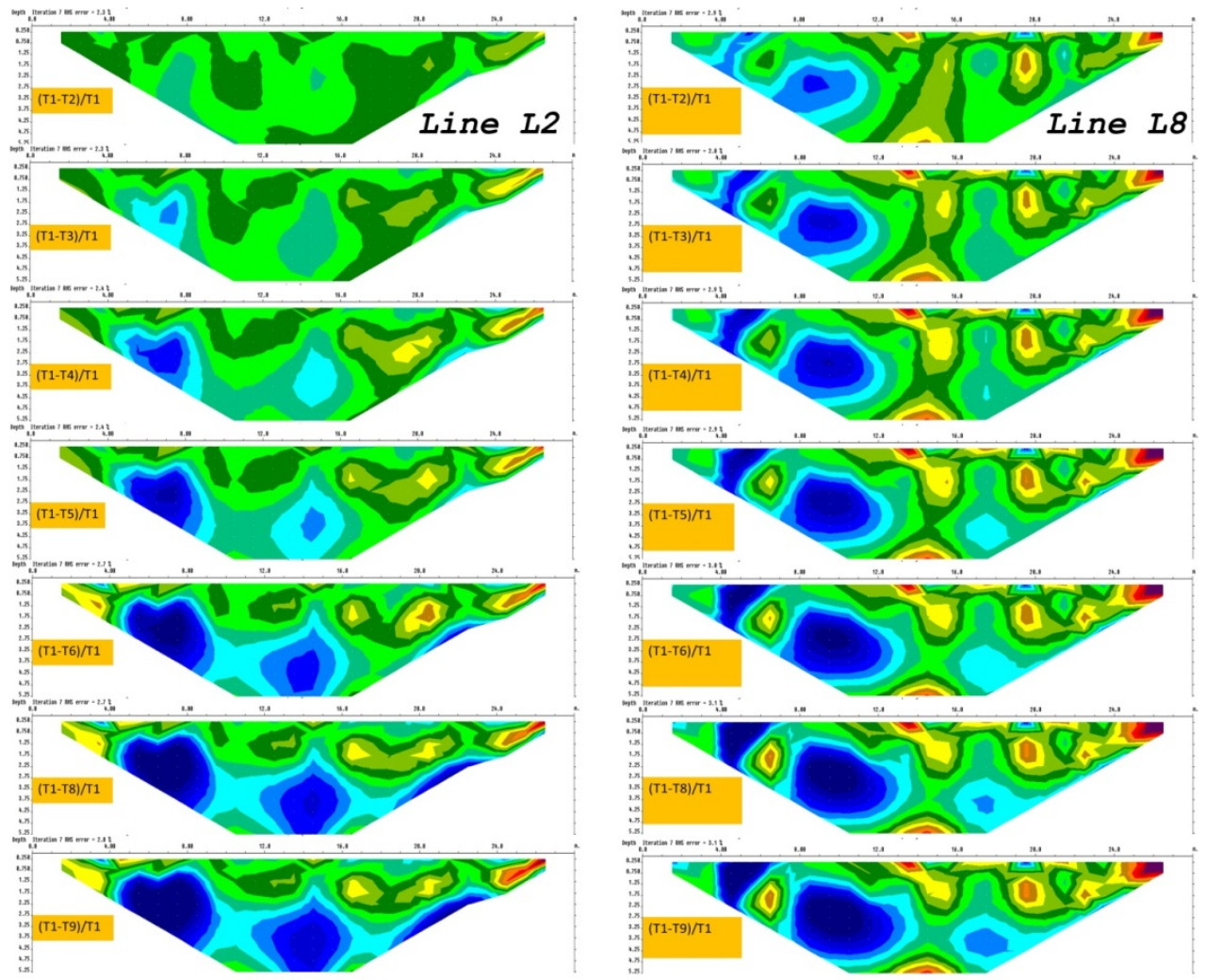



Figure 7. Sections of the \% subsurface resistivity change with time for phases T2 to T9 with respect to the reference phase T1 for Lines L2 and L8. Phase T7 was excluded from analysis due to erroneous data.

Afterwards the ERT images for Lines L2 and L8 showing the relative percentage change of resistivity of the later time phases (T2 to T9) with respect to the first phase (T1) were overlaid on the plan view of the site. The resistivity decrease along the 2-D sections reflects the water flow within the subsurface. This was projected on the ground surface in order to outline the preferred water flow paths within subsurface, at a depth of more than one meter. The water due to the leakage of the pipe shows a selective flow towards the east along three main paths (Fig. 8).

The resulting GPR slices for 1.0m depth are presented in Figure 10. GRID0 illustrates the subsoil before the water leakage starts. Two strong anomalies appeared at $Y=20 \mathrm{~m}, X=6-14 \mathrm{~m}$ and $Y=5$, 
$X=7-15 \mathrm{~m}$. These anomalies also appeared in all the phases after the leakage started. The difference is that both of the anomalies extend towards the location of the pipe that ejects the water. As well, the anomalies tend to be more linear in comparison with the dry soil, especially for GRID7 (Fig.9). It is clear that those displacements and changes of the anomalies' location and shape are due to the water leakage.



Figure 8. Outline of the footprint of water flow on the ground surface based on the results of the ERT monitoring experiment.

In Figure 10 and 11, the percentage difference of GRID0 and GRID1 respectively are presented. For the first case (Fig. 10) the differences in instantaneous amplitude don't exceed $50 \%$ and seems to be the same for all the phases. There is not a significant fluctuation of the amplitudes among the different phases to provide information related to the water paths propagation in time. The second case (Fig. 11) showed no changes in amplitude values. The water flow may have caused changes in the existing anomalies' shape and location but it didn't affect the amplitude values. 
52 Integrated Use of Space, Geophysical and Hyperspectral Technologies Intended for Monitoring Water Leakages in Water Supply Networks
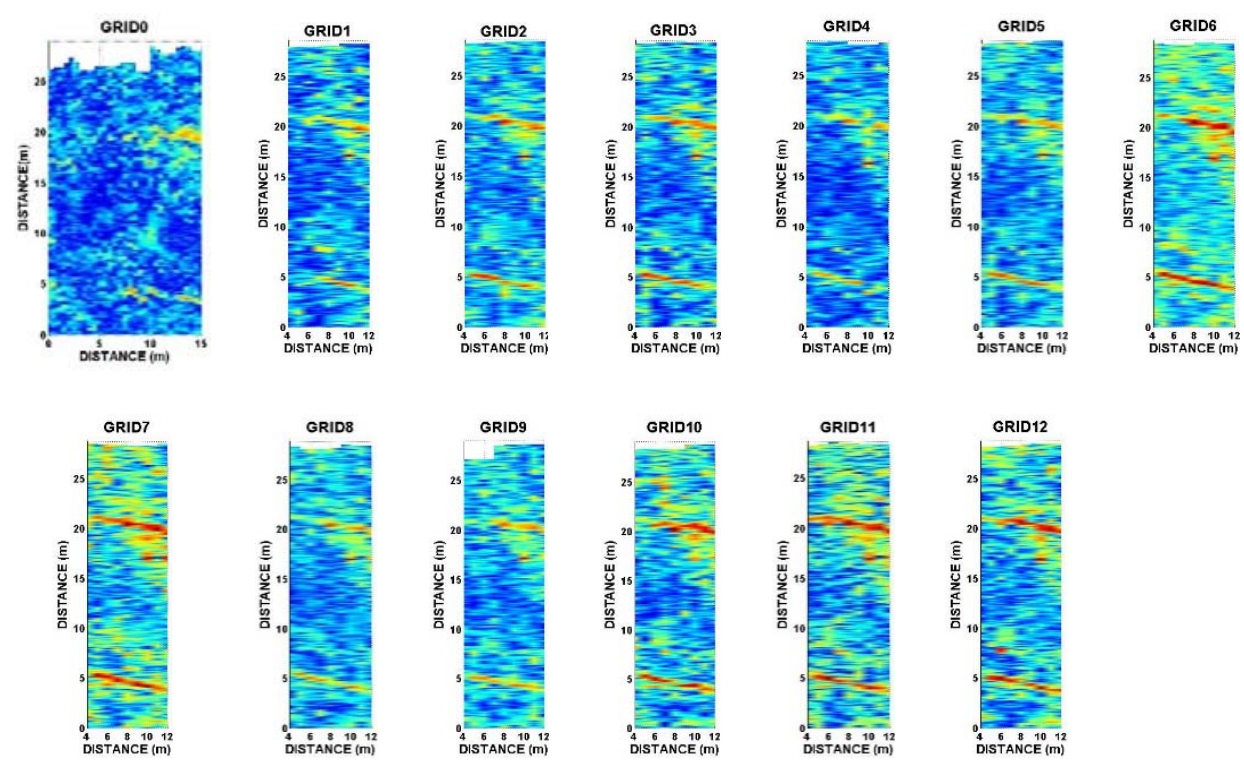

Figure 9. Resulting GPR slices during each phase for $1.0 \mathrm{~m}$ depth.
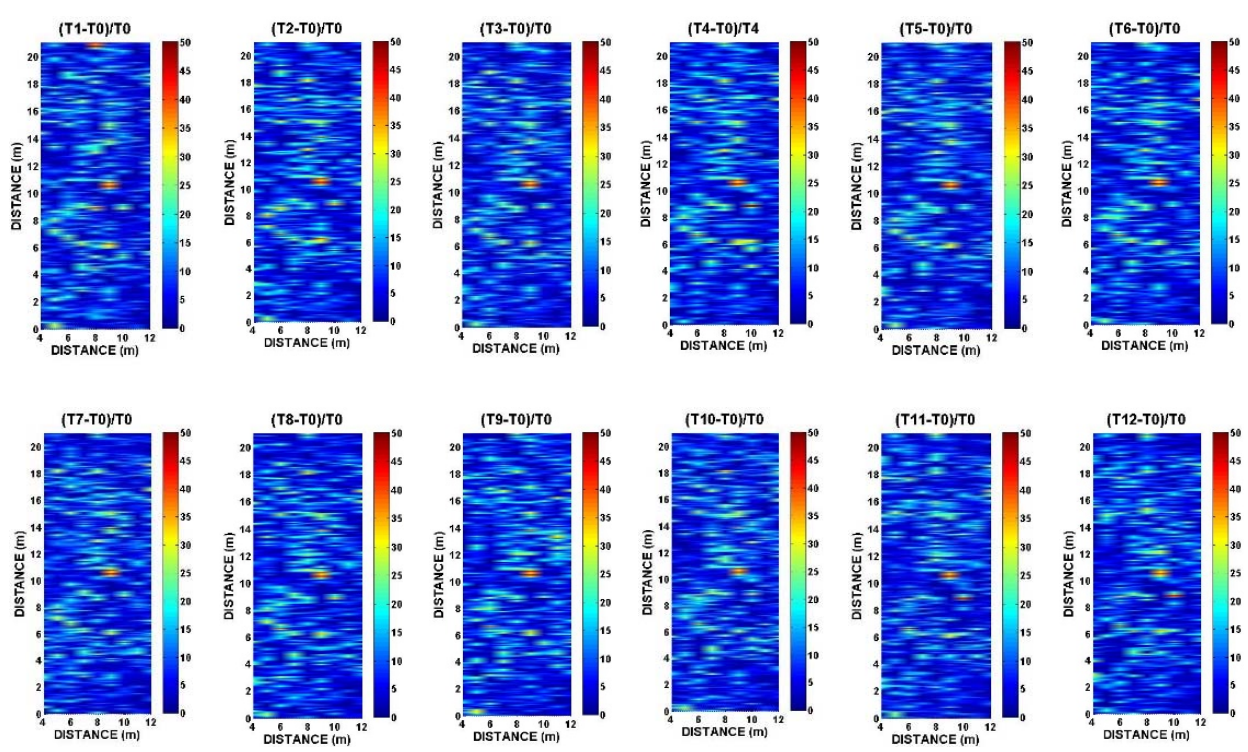

Figure 10. Percentage differences in respect to the first phase of dry soil. 

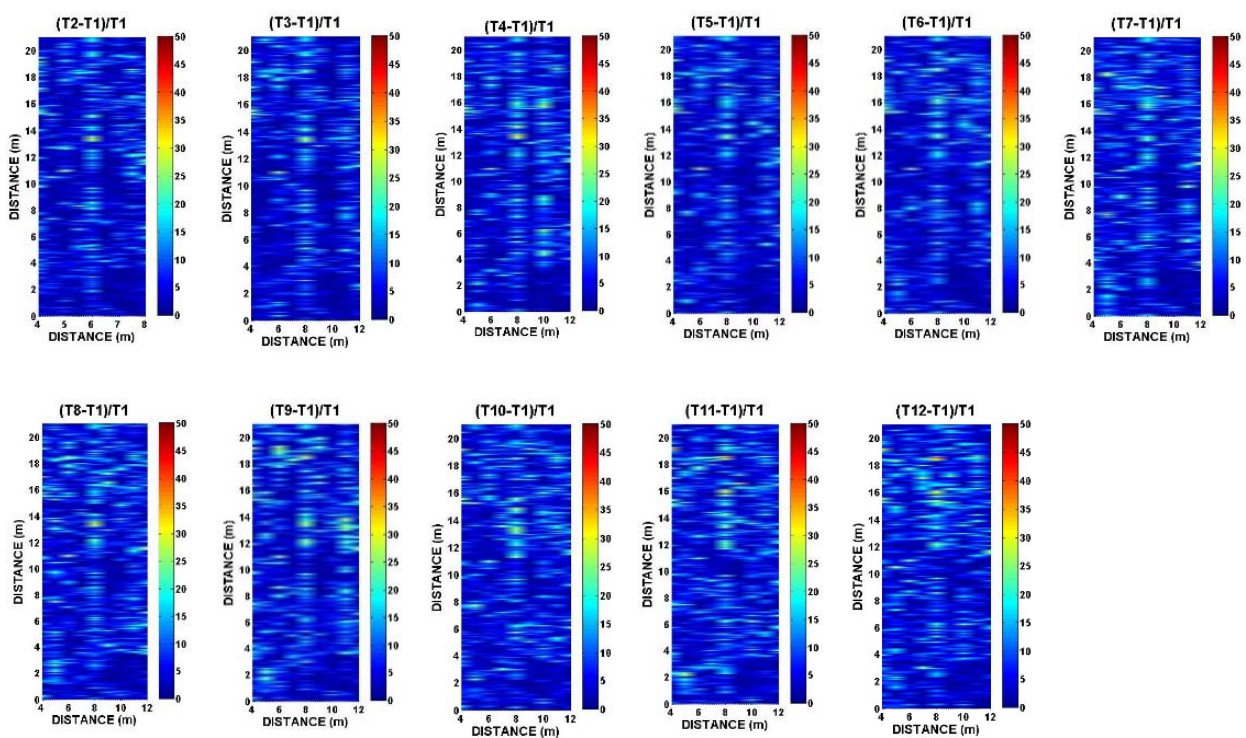

Figure 11. Percentage differences in respect to the second phase, during which the water leakage started.

\section{Conclusions}

The results of the controlled experiments demonstrated the effectiveness of ERT in locating and monitoring the water flow along preferred water paths. In contrast to ERT, GPR exhibited inferior results. The changes on the existing reflectors could not give a distinct signature in order to describe the water paths. This does not necessarily mean that GPR is not an appropriate method for monitoring water leakages. The poor results can be attributed to the fact that the water paths appear at a depth of more than $1.0 \mathrm{~m}$ where the conductivity is very high due to the presence of clay resulting increased absorption for the GPR signal.

\section{Acknowledgements}

The results reported here are based on findings of the Cyprus Research Promotion Foundation


spectral technologies intended for monitoring water leakages in water supply networks in Cyprus. The project is co-funded by the Republic of Cyprus and the European Regional Development Funds of the EU. 


\section{Author details}

Meropi Manataki ${ }^{1}$, Nikos Papadopoulos ${ }^{1}$, Apostolos Sarris ${ }^{1}$, Athos Agapiou ${ }^{2}$,

Kyriacos Themistocleous ${ }^{2}$ and Diofantos G. Hadjimitsis ${ }^{2 *}$

*Address all correspondence to: d.hadjimitsis@cut.ac.cy

1 Laboratory of Geophysical-Satellite Remote Sensing \& Archaeo-environment (GeoSat ReseArch), Institute for Mediterranean Studies (I.M.S), Foundation for Research \& Technology, Hellas (F.O.R.T.H.), Nik. Foka 130, Rethymno 74100, Crete, Greece

2 Department of Civil Engineering and Geomatics, Faculty of Engineering and Technology, Cyprus University of Technology, Cyprus

\section{References}

[1] Annan, A.P.. GPR- History, Trends and Future Developments. Subsurface Sensing Techonology Applied, 2002. 3: pp. 253-270.

[2] Aspinall, A and Lynam, J.T.. An induced polarization instrument for the detection of near-surface features. Propezioni Archaeologica, 1970. 5: pp. 67-75.

[3] Atzemoglou, A., Tsourlos, P., and Pavlides, S.. Investigation of the tectonic structure of the NW part of the Amynteon Basin (NW Greece) by means of a vertical electrical sounding (VES) survey. Journal of the Balkan Geophysical Society, 2003. 6: pp. 188-201.

[4] Benson, A.K. . Applications of ground penetrating radar in assessing some geological hazards: examples of groundwater contamination, faults, cavities.. Journal of Applied Geophysics, 1995. 33: pp. 177-193.

[5] Bimpas, M., Amditis, A., and Uzunoglu, N.. Detection of water leaks in supply pipes using continuous wave sensor operating at 2.45GHz. Journal of Applied Geophysics, 2010. 70: pp. 226-236.

[6] Cassidy, N.J. . Chapter 2 - Electrical and Magnetic Properties of Rocks, Soils and Fluids, in:Harry M. Jol (eds.). Ground penetrating Radar Theory and Applications. Amsterdam: Elsevier. 2009a. 41-72.

[7] Dahlin, T. and Owen, R.. Geophysical investigations of alluvial aquifiers in Zimbabwe, in: Proceedings of the IV Meeting of the Environmental and Engineering Geophysical Society (European Section). Barcelona, Spain. 1998. 151-154.

[8] Dahlin, T., Johansson, S., and Landin, O.. Resistivity Surveying for Planning of Infrastructure., in: Environment and Engineering Geophycial Society (eds.). Symposium on the Application of Geophyscis to Entigeering and Engineering Problems. 1994. 509-528. 
[9] Davis, J.L. and Annan, A.P.. Ground- Penetrating Radar for High-resolution Mapping of Soil and Rock Stratigraphy. Geophysical Prospective, 1989. 37: pp. 531-551.

[10] Doolittle, J.A., Jenkinson, B., Hopkins, D., Ulmer, M. and Tuttle, W. . Hydropedological investigations with ground penetrating radar (GPR): Estimating water-table depths and local ground-water flow pattern in areas of coarse-textured soils. Geoderma, 2006. 131: pp. 317-329.

[11] El-Said, M.A.H.. Geophysical Prospection of Underground Water in the Desert by Means of Electromagnetic Interference Fringes. Proc. IRE, 1956. 44: pp. 24-30.

[12] Grasmueck, M.. 3-D ground-penetrating radar applied to fracture imaging in gneiss. Geophysics, 1996. 61: pp. 1050-1064.

[13] Hunaidi, O., Chu, W., Wang, A., and Guan, W. . Leak Detection Methods for Plastic Water Distribution Pipes, American Water Works Association. 1999.

[14] Jordana, J., Gasulla, M., and Pallas-Areny, R.. Electrical resistance tomography to detect leaks from buried pipes. Measuring Science Technology, 2001. 12: pp. 1061.

[15] Karaoulis, M.C., Kim, J.H. and Tsourlos, P.I. . 4D active time constrained resistivity inversion. Journal of Applied Geophysics, 2011. 73: pp. 25-34.

[16] Kim, J.H., Yi, M.J., Park, S.G. and Kim, J.G.. 4-D inversion of DC resistivity monitoring data acquired over a dynamically changing earth model. Journal of Applied Geophysics, 2009. 68: pp. 522-532.

[17] Legault, J.M., Carriere, D., and Petrie, L. . Synthetic model testing and distributed acquisition dc resistivity results over an unconformity uranium target from the Athabasca Basin, northern Saskatchewan.. The Leading Edge, 2008. 27: pp. 46-51.

[18] Loke, M. and Barker, R.D.. Rapid least-squares inversion of apparent resistivity pseudosections by a quasi-Newton method. Geophysical Prospective, 1996. 44: pp. 131-152.

[19] Loke, M., Acworth, I. and Dahlin, T.. A comparison of smooth and blocky inversion methods in 2D electrical imagining surveys.. Exploring Geophysics, 2003. 34: pp. 182-187.

[20] Mares, S.. Introduction to Applied Geophysics. Sppringer Science and Business Media. 1984.

[21] Panissod, C., Dabas, M., Hesse, A., Jolivet, A., Tabbagh, J., and Tabbagh, A. . Recent developments in shallow-depth electrical and electrostatic prospecting using mobile arrays. Geophysics, 1998. 63: pp. 1542-1550.

[22] Papadopoulos, N. Sarris, A., Yi, M. and Kim, J. . Urban archaeological investigations using surface 3D Ground Penetrating Radar and Electrical Resistivity Tomography Methods. Exploring Geophysics, 2009. 40: pp. 56-68. 
[23] Papadopoulos, N.G., Tsourlos, P., Tsokas, G.N. and Sarris, A.. Two-dimensional and three-dimensional resistivity imaging in archaeological site investigation.. Archaeological Prospective, 2006. 13: pp. 163-181.

[24] Papadopoulos, N.G., Tsourlos, P., Papazachos, C., Tsokas, G.N., Sarris, A. and Kim, J.H.. An algorithm for fast 3D inversion of surface electrical resistivity tomography data:application on imaging buried antiquities. Geophysical Prospective, 2011. 59: pp. 557-575.

[25] Powers, M.H., and Olhoeft, G.R. . Moeling the GPR Response of Leaking, Buried Pipes. EEGS, 1996. : pp. 525-534.

[26] Ramirez, A., Daily, W., Binley, A. and LaBrecque, D. . Tank Leak Detection Using Electrical Resistance Methods, in:Environment and Engineering Geophysical Society (eds.). Symposium on the Application of Geophysics to Engineering and Environmental Problems. Environment and Engineering Geophysical Society. 1996. 763-772.

[27] Spanoudakis, S.N. and Vafidis, A. . GPR-PRO: A MATLAB module for GPR data processing, in:Proceedings of the 2010 13th International Conference on ground Penetrating Radar (GPR). 2010. 1-5.

[28] Spanoudakis, N.S., Manataki, M., Niniou-Kindeli, V. and Vafidis, A.P. . GPR Imaging at Aptera Archaeological Site, in:Proceedings of the 6th Congress of Balkan Geophysical Society. 2011.

[29] Stampolidis, A., Soupios, P., Vallianatos, F. and Tsokas, G.N.. Detection of leaks in Buried plastic water distribution pipes in urban places-a case study, in:Proceedings of the 2nd International Workshop on Advanced Ground Penetrating Radar. 2003. 120-124.

[30] Theune, U., Rokosh, D., Sacchi, M. and Schmitt, D.. Mapping fractures with GPR: A case study from Turtle Mountain.. Geophysics, 2006. 71: pp. B139-B150.

[31] Tzanis, A.. Matgpr: a freeware matlab package for the analysis of common-offset GPR data.. Geophysical Research Abstracts,

[32] Vaughan, C. . Ground-peentrating radar surveys used in archaeological investigations. Geophysics, 1986. 51: pp. 595-604.

[33] Weymouth, J.W. and Huggins, R.. Geophysical Surveying of Archaeological Sites, in:Rapp, G and Gifford, J. (eds.). Archaeological Geology. 1985. 191-236. 